\title{
Microeconomic Analysis of the Informal Sector- Results of Sample Surveys
}

\author{
S. I. Cohen and Ivo C. Havinga*
}

\section{INTRODUCTION}

In earlier studies of the informal sector, and in particular in its association with small-scale, cottage and household manufacturing industries (HM), this sector was commonly considered as economically backward, low-income and offering few possibilities for raising productive employment. Later studies, by Allal and Chutta (1982) questioned this view, and noted, in addition, that informal activities are an important source of income and employment for a large portion of the population and will remain so over a long period to come and cannot be neglected, therefore, in the design of development policies.

The recognition of the importance of this sector has not removed two major obstacles in the investigation of the sector: data and viable analytical frameworks. Additional insight in the sector requires primary data collection of an unregistered population, and developing an analytical framework for studying settings with significant institutional influences. This paper reports on the collection of primary data and on an analytical framework which were applied in a field survey of the informal sector in the context of urban areas in Pakistan.'

It is plausible to define the informal sector as consisting of firms at the lower end of the size continuum. However, it will be apparent in a field survey that these establishments are still highly diversified and do include establishments which are mainly linked to the modern part of the economy, and which can be called ML, and establishments which are more of the self-sufficient type with only incidental links with the modern economy, which we shall call SS.

*The authors are respectively, Professor of Economics and Senior Lecturer at the Erasmus University, Rotterdam.

'A full report is found in Cohen and Havinga (1984). At this point it is important to refer to a similar study of a sample survey of non-farm employment in rural areas Cohen and van Elk. (1984). 
The proposition to subdivide the surveyed establishments into two subsamples is not to be interpreted in the sense that the informal sector contains two independent circuits. On the contrary, there is a graduation between prototypes. In the Seventies and early Eighties, [Bienefeld (1987); Bose (1974); Breman (1976)], among others, argued that the informal sector must be dealt with as a coherent economic system which contains different modes of production varying in degree and graduation in their production behaviour, factor use, marketing pattern and institutional aspects. Therefore, when operationalizing a subdivision into two subgroups, the approach followed should give thought to the fact that the profiles of firms are multi-dimensional and tend to polarize consistently only in the extremes.

The analytical framework permits the investigation of profiles of establishments at various levels: (1) the segmental level as proposed above in the form of ML versus SS, (2) the city level, (3) the sector of activity, and (4) occupational level. In principle, policy intervention can be also applied at all four levels. For reasons of space this paper, however, will concentrate on the segmental level, a further examination of all levels is found in Cohen and Havinga (1984)

Before presenting the statistical and analytical framework it is worthwhile to comment on the significance of the informal sector with regard to employment and income generation. It is plausible to assume that 70 percent of the employment in manufacturing activities are taken up by household manufacturing for a country like Pakistan. In fact, applying the development characteristics of Pakistan to the cross-section curves estimated by Anderson (1982), renders such a magnitude. This percentage is confirmed by an urban study from Guisinger and Irfan (1980) which expressed that 70 percent of the urban labour force is employed in the informal sector.

The paper will be organized as follows. In Section 2 the distinction between the subgroup ML and SS will be discussed and applied. The main features of SS and ML will be presented in Section 3 along various types of indicators. More specific attention will be devoted to the efficiency indicators by means of the estimation of production functions in Section 4. The equity indicator is highlighted in Section 5 followed by concluding remarks in Section 6 .

\section{DIFFERENT SEGMENTS WITHIN HM: SUBDIVISION OF TOTAL SAMPLE INTO SUB-SAMPLES}

The sample survey referred to in this paper has been conducted in 1980 in four cities of Pakistan: Lahore, Karachi, Peshawar, Rawalpindi. The actual field work is divided in two parts: (1) a short screening survey of informal activities based on three questions; and (2) the elaborate sample survey based on a long questionnaire. For the screening survey, as many small-scale firms as possible were recorded in a particular area and were requested to respond according to the following three questions: (a) type of activity;

(b) total number of workers in firm; and

(c) number of owner and family workers in firm.

Firms active in manufacturing not exceeding five workers and the majority of workers are owner and self-employed, are subjected to the long questionnaire. An interview took between 20 to 40 minutes. The interviews produced 806 valid responses at establishment level.

The heterogeneity of the sample and its positioning between formal and informal market processes calls for the subdivision of the sample into two subsamples. The subdivision of the sample will also help illustrate the changing profiles of establishments at the lowest size continuum of firms consistent with differen phases of industrial development. At the one hand the traditional segment con tains family-based firms with forward and backward linkages usually to the loca consumer market. In contrast, the more formal segment has traits in common with the modern sector, this segment employs non-family labour and maintains backward and forward linkages with the rest of the economy. As a result, higher income generation might be expected as well as larger diffusion of technical and manageria information.

Placed in the historical transformation of firms, a part of the locally oriented SS-firms gradually transforms in outward oriented ML-firms so that both types of firms have different and similar features. Therefore a sliding scale of five indicators has been designed to allow a subdivision which guarantees the contrasts and similarities of features.

Table 1 lists the five indicators which are applied to separate the subgroups SS and ML. The supply side, i.e. production, is represented by indicators labelled labour, raw materials and capital. The demand side, i.e. market, is represented by the indicator labelled product, while the institutional aspects are represented by the indicator registration of establishment.

Considering first the supply side, the indicator for labour distinguishes between family-based firms and those firms with one or more non-family (wage) earner(s) The indicator raw material serves to distinguish between outward-backward relation and inward-backward relations where the outward-backward linkages are determined by the relations with wholesalers, middlemen, government agencies and the mix of all the raw material markets. The locally inward-oriented backward linkages ar highlighted by the relations with farms, households and retailshops. Finally, the indicator capital displays the difference in capital investment of firms below and above the average capital investment of the total sample, i.e. 6500 Pakistani Rupees.

The indicator on demand for products differentiates between the outward and inward forward linkages, resp. sales of product to large and small enterprises 
Table 1

Indicators, Threshold Values and Results of the Subdivision of Household Manufacturing (HM) in the Mainly Linked (ML) and the Substantially Self-con tained (SS) Sub group

Results of the Subdivision into Two Samples Number of Units Falling in

Indicator and Threshold Value Each Sample

Substantially Mainly Linked

Self-contained

(SS)

\section{Supply}

1. Labour (NUMFA)

Number of Non-family Workers:
(a) Zero
(b) One or More

2. Raw Material (RAWORI)

Supply of Raw Materials from:
(a) Inward Source
(b) Inward and Outward Sources

3. Capital (CAPVAL)

Fixed Capital Investment:

(a) Less than Rs 6,500

(b) Equal or More than Rs 6,500

\section{Demand}

4. Product (DEMMAR)

Sales of Products to:

(a) Inward Oriented Markets

(b) Inward and Outward Oriented Markets

\section{Establishment}

5. Registration (ESTREG)

Whether Enterprise is Legally Registered:
(a) No

(b) Yes and government agencies (outward), and sales to households and farmers (inward).

The indicator on establishment characteristics differentiates between those firms with and without a legal registration of the firm.

For each of the above five indicators threshold values are specified. An establishment falling below the threshold value is assigned tentatively to the SS segment, while an establishment falling above the threshold value is assigned tentatively to the ML segment. If an establishment is assigned twice or more times to the ML segment then it is counted as definitely belonging to the ML segment. All other establishments are then counted as belonging to the SS segment. Applying the minimum of two indicators, the subdivision results into the grouping of 153 firms (19.0 percent) in the ML-subgroup and 653 firms (81.0 percent) in the SS-group.

When looking at the discriminating ability of each indicator, one notices that the indicator of non-family worker(s) in the firm (NUMNFA) performs better than other indicators in separating the sample into two sub-samples, i.e. 109 firms are identified as ML which is the highest value in column 3, Table 1. Next in discriminating ability is the indicator relating to origin of the raw materials (RAWORI), followed by the indicators on sales markets (DEMMAR), legal registration (ESTREG), and finally capital investment (CAPVAL).

\section{MAIN FEATURES OF THE DISTINGUISHED SEGMENTS}

That the subdivision in SS and ML provides an appropriate basis to verify different profiles from SS to ML can be perceived from the empirical results presented in Table 2.

The formal nature of establishments in the ML-segment as compared to those in the SS-segment is directly perceived from the higher percentage of registration (ESTREG) and use of bookeeping records (ESTREC). Moreover, the LM-firms with their outward market orientation obtain higher demand for their products. This is counterbalanced by higher capital investment (CAPVAL) and higher total employment (LABSIZ). The higher employment necessitates recruiting non-family wage earners (LABNOF) and apprentices (LABAPP). A higher average capital labour intensity (RELINT) for ML-firms is observed. Also a higher average labour productivity (PROLAB) is realized. Since instability of demand is reported to be relatively higher by the ML-firms due to the outward orientation of the sales markets, the ML-setting is characterized by an underutilization of the capital investment, which explains the lower average capital productivity (PROCAP).

This combination of a higher capital/labour intensity, a higher labour productivity and a lower capital productivity is consistent with factual evidence elsewhere. Findings on small-scale enterprises from other countries Havinga, Faiz and Cohen (1986) show that (1) small enterprises with lower level of capital endowment 
Table 2

Segmental Profiles of ML and SS

LABOUR

LABSIZ LABFAM LABNOF LABAPP LABPAY LABTON LABTSK

SUB-

GROUP

1. $M L$
2. SS

3. TOTAL

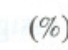

$(\%)$

(\%)

(\%)

$(\%)$

(\%)

(\%)

3.2
2.5

90

10

20

0

58.6

4.2
2.8

23.3
17.0

63.

CAPITAL RAW MATERIALS

CAPVAL RAWLIC RAWORI RAWDIF EN

SUB-

GROUP

CAPVAL RAWLIC

$$
\text { RAWORI RAWDIF ENRELE }
$$

1. ML

2. SS

$\begin{array}{ll}(\%) & (\%) \\ 53.2 & 22.6 \\ 20.7 & 16.8\end{array}$

$(\%)$
64
9

64.2

(\%)

(\%)

$30.2 \quad 93.9$

$\begin{array}{lll}9.1 & 21.2 & 87.5\end{array}$

3. TOTAL $29.5 \quad 17$

TECHNOLOGY

TECAPP TECKNO RELINT PROCAP PROLAB

SUB-

GROUP

1. ML

$(\%)$

64.1
41.7

(\%)

RELINT

3. TOTAL

\begin{tabular}{cccc}
$(\%)$ & $(\%)$ & $(\%)$ & \multicolumn{1}{c}{ (Rs) } \\
61.0 & 5296.5 & 2.68 & 14214.5 \\
40.1 & 2151.4 & 4.34 & 9333.3
\end{tabular}

DEMAND

3.54

10674.3

ESTABLISHMENT

SUB-

GROUP

DEMDEM

ESTREG ESTREC

1. $\mathrm{ML}$
2. $\mathrm{SS}$

3. TOTAL 66.0

$(\%)$
41.1
30.3
32.4

$(\%)$
26.1
24.3
24.7

$\begin{array}{ll}(\%) & (\%) \\ 78.6 & 43.1 \\ 82.7 & 11.5 \\ 81.8 & 17.5\end{array}$

(\%)

43.9

30.0

OWNER OBJECTIVE

OWOEDU OWOING

SUB-

GROUP

1. $\mathrm{ML}$

(Years)

$\begin{array}{lll}\text { 2. } \text { SS } & 8 & 20240.7 \\ \text { 3. TOTAL } & 7 & 12436.0\end{array}$

$\begin{array}{lll}\text { 3. TOTAL } & 7 & 13999.2\end{array}$

OWNER SUBJECTIVE

OWSFUT OWSEXP OWSCOM OWSCAP OWSUNO

SUB-

GROUP

2. SS

3. TOTAL

$\begin{array}{ll}(\%) & (\%) \\ 62.6 & 48.9 \\ 60.4 & 41.5 \\ 60.9 & 42.9\end{array}$

$\begin{array}{llr}(\%) & (\%) & (\%) \\ 67.1 & 84.4 & 20.0 \\ 66.6 & 81.3 & 7.6 \\ 66.7 & 81.9 & 10.1\end{array}$

per worker tend to realize a lower productivity of labour than the larger more capital intensive enterprises, and (2) small enterprises with lower level of investment per worker tend to achieve a higher productivity of capital than do larger and more capital intensive enterprises.

The higher instability of demand, both structural (DEMDES) and conjunctural (DEMDEM), is also revealed by the higher turnover of skilled (LABTSK) and un skilled (LABTUN) workers. The higher level of uncertainty of demand could also explain the shift in the nature of work to higher incidence of payment (LABPAY) on the number of pieces produced instead of fixed appointment.

Illustrative of the effect of outward orientation is both the increasing difficulty in obtaining raw materials (RAWDIF) outside the district (RAWORI) as well as the increased requirement for delivery licences of raw materials (RAWLIC). Similarly, a larger part of the technical know-how (TECHNO) is diffused through suppliers and government agencies as compared to family and friends, leading to a widening of knowledge regarding applicability of mechanized production (TECAPP). Furthermore, the evidence of more outward oriented sales markets (DEMMAR) might explain the higher tendency towards sales on credit (DEMCRE) and sales from stocks (DEMORD). At least, the latter indicates the tendency towards larger working capital. Incidentally, almost all firms surveyed have connections to the electric grid system (ENRELE).

For the owner of the ML-firms compared to the SS-firms, one observes on average 66 percent higher income (OWOINC) and 2 years more education (OWOEDU). Also he is more aware of already existing possibilities of government assistance (OWSUNO). With respect to this assistance he has a positive attitude towards paying for this assistance (OWSPAY). More competition (OWSCOM) and overcapacity (OWSCAP) are also felt by the owner of the ML-firm, but he is stil more optimistic about future development (OWSFUT). Possibly due to these better future expectations, he expresses a higher intention to expand (OWSEXP) his production than the owner of a SS-firm.

Finally, that the above-mentioned instabilities at the demand side also result in vulnerability at the supply side can be clearly noted when comparing the ML and SS profiles of the encountered problems at the time of the establishment of the firm and at present, in Tables 3 and 4. Owners of SS-firms perceive the lack of finance and demand both at start and at present as the major problems. The outward orientation of ML-firms, however, results in a different perception of problems The lack of finance is again mentioned for the initial phase but also the lack of skilled labour and raw materials next to the lack of demand are significant. These problems tend to persist till present although a changing hierarchy can be observed: in particular with regard to the lack of raw materials. 
Table 3

Substantially self-contained (SS): Hierarchy of Encountered Problems at Start and Present. Percentage of Firms Facing Problems

\begin{tabular}{lcc}
\hline Type of Problem & At Start & At Present \\
\hline Some Problem(s), of which & 63.0 & 63.6 \\
Lack of Finance & 44.6 & 39.5 \\
Lack of Demand & 33.8 & 37.2 \\
Lack of Raw Materials & 6.8 & 11.6 \\
Lack of Skilled Labour & 5.1 & 5.7 \\
Lack of Suitable Location & 4.1 & 4.2 \\
Hardship of Work & 1.6 & 2.7 \\
Inavailability of Equipment & 0.0 & 2.3 \\
Not Specified & 3.5 & 6.9 \\
\hline
\end{tabular}

Table 4

Mainly Linked (ML): Hierarchy of Encountered Problems at Start and Present. Percentages of Firms Facing Problems

\begin{tabular}{lcc}
\hline Type of Problem & At Start & At Present \\
\hline Some Problem(s), of which & 57.6 & 71.7 \\
Lack of Finance & 41.1 & 27.4 \\
Lack of Demand & 17.1 & 20.7 \\
Lack of Skilled Labour & 20.6 & 14.2 \\
Lack of Raw Materials & 11.8 & 29.7 \\
Inavailability of Equipment & 1.4 & 1.1 \\
Hardship of Work & 1.4 & 1.1 \\
Lack of Suitable Location & 0.0 & 0.0 \\
Not Specified & 5.9 & 5.4 \\
\hline
\end{tabular}

\section{PRODUCTION RELATIONSHIPS IN HOUSEHOLD MANUFACTURING}

There is a rational urge to formalize some of the foregone profile descriptions in systematic cause-effect functions. The production function is a suitable framework for studying capital and labour use. Parameters of the production function give the marginal productivities of additional uses of labour and capital.
While various forms of production functions can be specified, the Cobb Douglas production function is most oftenly used and suffices the purpose in the present context.

Several specifications of the Cobb-Douglas function have been estimated. In the first place, we have

$$
\ln V A L_{i}=A+a \cdot \ln L A B S I Z_{i}+b \cdot \ln C A P I T A L_{i}+u_{i}
$$

where for each firm $i, V A L$ is the total net value added, $L A B S I Z$ is total employment, CAPITAL is total fixed capital at historical prices. The coefficients $a$ and $b$ are factor elasticities and $u$ is the error term. In addition, the age and educational characteristics of workers and owners have been introduced. $O W E D$ is formal education of owner, $O W E X$ is the age of the owner as a proxy for experience of the owner, $A V E D$ is the average formal education of workers, $A V E X$ is the average age of workers as a proxy for average experience of workers.

The underlying premise for differentiating between education and experience is based on the hypothesis that in HM with its low level of organization and management, experience is more of direct use due to the improvement of skills and the effects on technological change than formal schooling.

The distinction between the variables of the owner and workers has been made in order to consider the fact that the nature of production in HM is such that it does not reveal clear signs of division of labour. Therefore, the average accumulation of education and in particular experience has more explanatory value for the differences in value added than the level of education and skills (experience) of the owner.

Table 5 gives the estimations of the alternative functions for the total sample and for ML and SS.

It is apparent that the statistical performance of the regressions is rather poor in terms of the explained variances $\left(R^{2}\right)$, although they increase slightly with the introduction of the measure of education and experience in the function.

The poor performance can be due to the manner of estimation of the capital stock; for instance, by taking the historical price of capital one does not differentiate between the marginal capital productivities of different vintages: while the consider able mixture of capital equipment found in HM may obstruct a standardized valuation of that capital.

A more significant explanation lies in the already observed fact that firms in HM with high and sometimes redundant capital and without a correspondingly high total value added tend to reduce the size of the estimated coefficients of the capita elasticity. In many cases the coefficients of capital elasticity are low and insignificant or significant only at 20 percent level, not only for the total sample, but also for the subsamples of ML and SS. It was not possible to make allowance for the 


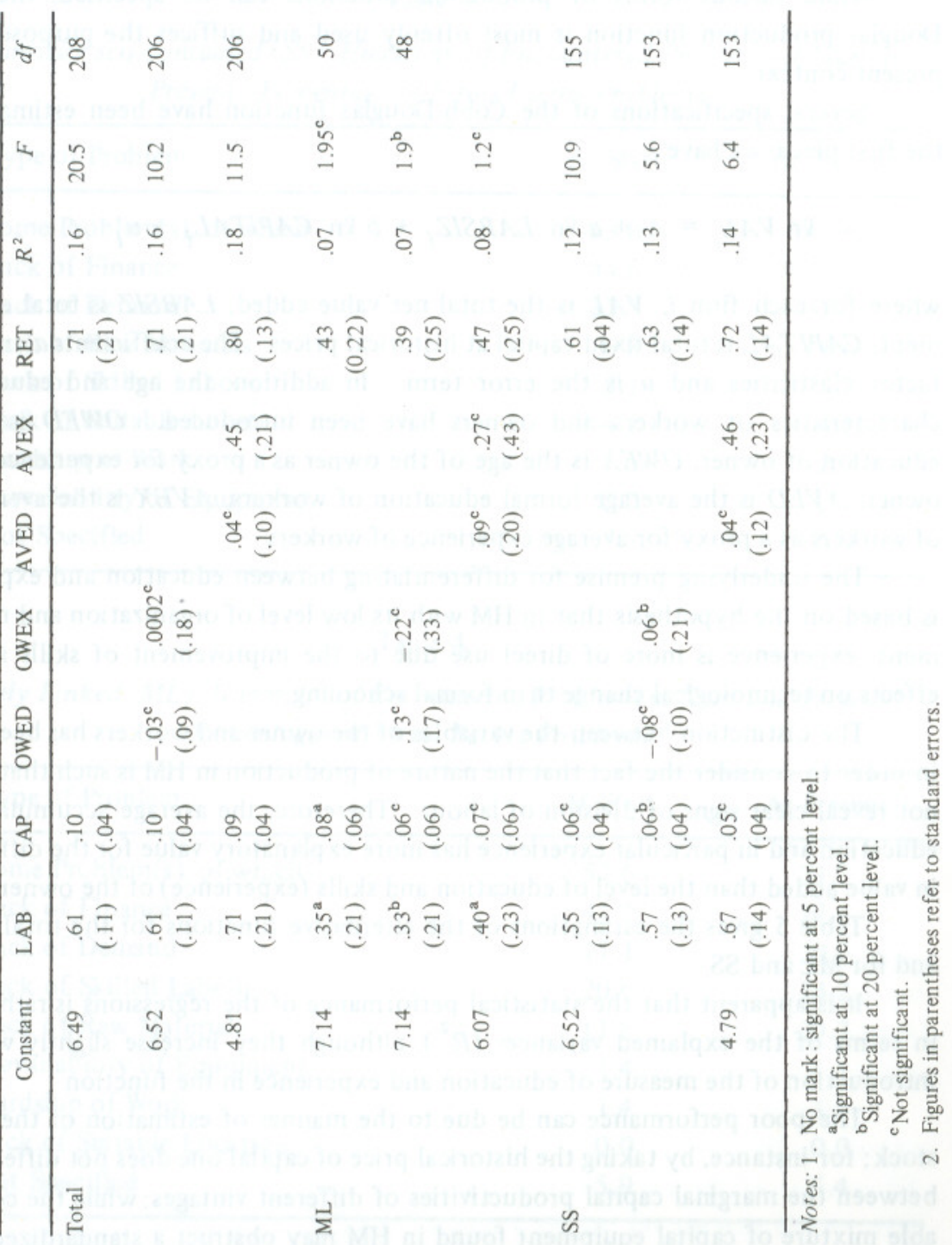

degree of capital underutilization.

Coefficients of the labour elasticity show higher rates for the SS-segment than for the ML-segment ranging from .55 to .67 and .33 to .40 respectively, for alternative specifications. The results are significant (at least at 10 percent level) and stable.

As regards the educational variables, it is observed that experience is found to be more important than formal education, for both the owner and the average worker given the present level of organization and technology of HM.

\section{DISTRIBUTIONAL ASPECTS IN HOUSEHOLD MANUFACTURING}

In the development process of the HM, limited policy instruments are available to transfer efficiency gains from gainers to losers. The harmonization of equity and efficiency, and for that matter the limitation of trade-offs between equity and efficiency should be appreciated by policy-makers. In case conflicting situation arise structural adjustments should be contemplated to allow balanced growth.

Two measures of income inequality have been constructed. The first measure, $x$, has been labelled average personal income inequality which relates average income of total workers to the average income of the owners. This measure has been appropriately modified by considering the number of dependents supported by a given income, which leads to the second measure, $y$, labelled the average family inequality.

The application of the two ratios is taken up in Table 6. For ratio $x$, one obtains a value of 57 percent for $\mathrm{ML}$ and 76 percent for SS, hence, the income inequality between the workers and owners is more pronounced for ML than SS. Yet, when we introduce the number of dependents, the modified ratio, $y$, becomes 93 percent for ML and 107 percent for SS. So, the distribution of family income after considering dependents, is highly equal in both the ML and SS subsamples.

Having looked at the average personal and family income inequalities within ML and SS, it is interesting to illustrate these average income inequalities between $M L$ and SS, Table 7. The inequality ratio between the average owners of SS and ML is 61 percent while the inequality between the average workers of SS and ML is 81 percent. When multiplying straightforward with the dependency ratios of the average workers of $M L$ and SS and the average workers of ML and SS, the ratio of the average family income inequality between the average owners of SS and ML is still 61 percent and between the average workers of SS and ML gives 71 percent. Hence, the average family income inequality between workers of ML and SS is larger than the average personal income inequality between workers of ML and SS.

Although the income inequality between the owners of ML and SS remains the same with or without dependents, we note an increase in inquality if the element of other jobs elsewhere is introduced. Namely, the share of owners with other jobs 
Table 6

Measurements of Income Inequality within Segments

\begin{tabular}{llccc}
\hline $\begin{array}{l}\text { Measurement } \\
\text { of Inequality }\end{array}$ & $\begin{array}{c}\text { Type of } \\
\text { Sample }\end{array}$ & $\begin{array}{c}\text { Whole } \\
\text { Sample } \\
\text { (in Percent) }\end{array}$ & $\begin{array}{c}\text { Mainly } \\
\text { Linked } \\
\text { (ML) } \\
\text { (in Percent) }\end{array}$ & $\begin{array}{c}\text { Substantially } \\
\text { Self-contained } \\
\text { (SS) }\end{array}$ \\
\hline
\end{tabular}

1. Ratio of Labour Income from Personal Standpoint (without Dependents)

$\mathrm{LABINC}_{\mathbf{i}}$

OWOINC

2. Ratio of Labour Income from Family Standpoint (with Dependents)
LABINC $_{\mathrm{i}}$
$\frac{\text { OWODEP }_{i}}{\text { LABDEP }_{i}}$
102.6
92.7
107.0

LABINC = Average income of worker (including owner)

OWOINC $=$ Average income of Owner.

LABDEP = Average number of dependents of worker (including owner).

OWODEP $=$ Average number of dependents of owner.

i $=$ Each firm

Table 7

Measurements of Income Inequality between Segments, in Percent for Whole Sample

\begin{tabular}{llllll}
$\frac{\text { LABINC }_{S S}}{\text { LABINC }_{M L}}$ & 81.5 & $\frac{\text { OWOINC }_{S S}}{\text { OWOINC }_{M L}} \cdot \frac{\text { LABDEP }_{M L}}{\text { LABDEP }_{S S}}$ & 71.0 \\
$\frac{\text { OWOINC }_{S S}}{\text { OWOINC }_{M L}}$ & 61.4 & $\frac{\text { OWOINC }_{S S}}{\text { OWOINC }_{M L}} \cdot \frac{\text { OWODEP }_{M L}}{\text { OWODEP }_{S S}}$ & 61.4 \\
\hline
\end{tabular}

elsewhere in ML is larger than in SS, i.e., 14.2 percent and 8.7 percent, respectively.

\section{CONCLUDING REMARKS}

Empirical evidence shows the existence of significant segmentation of establishments in the informal sector. The paper has developed a viable analytical tool to distinguish firms belonging to an inward oriented and self-sufficient segment from an outward market oriented segment. Such a segmentation approach will facilitate adopting differential policy-making for each segment and, eventually, in anticipation of a transformation of profiles from one type to another.

The data base at hand does not permit analysis of the mobility pattern of firms or individuals between the two segments. Elaborations in this area of research are found elsewhere Havinga, Faiz and Cohen (1986).

\section{REFERENCES}

Allal, M., and E. Chutta (1982). Cottage Industries and Handicrafts: Some Guidelines for Employment Promotion. Geneva: ILO.

Anderson, D. (1982). "Small Industry in Developing Countries: Some Issues". Washington, D.C.: The World Bank. (World Bank Staff Working Paper No. 518)

Bienefeld, M. (1987). "The Informal Sector and Pheripheral Capitalism: The Case of Tanzania". Institute of Development Bulletin. Vol. 6, No. 3.

Bose, A. N. (1974). The Informal Sector in the Calcutta Metropolitan Economy. Geneva: ILO.

Breman, J. C. (1976). “A Dualistic Labour System?”. Economic and Political Weekly. Cohen, S. I., and I. Havinga (1984). Profiles of Informal Employment in Urban Area; A Sample Survey of Small-size Household Manufacturing in Main Urban Areas in Pakistan. Islamabad: Manpower Division.

Cohen, S. I., and K. van Elk (1984). Non-Farm Employment in Rural Pakistan: A Pilot Survey of 25 Villages. Islamabad: Manpower Division.

Guisinger, S., and M. Irfan (1980). "Pakistan's Informal Sector". Journal of Development Studies. Vol. 6, No. 4.

Havinga, I., Faiz M. and S. I. Cohen (1986). "Intergenerational Mobility and Long Term Socio-economic Change in Pakistan". Pakistan Development Review. Vol. XXV, No. 4. 


\section{Comments on \\ "Microeconomic Analysis of the Informal Sector - Results of Sample Surveys"}

The paper entitled "Micoreconomic Analysis of the Informal Sector - Results of Sample Surveys" by I. Havinga and S.I. Cohen makes a very important contribution to the very limited empirical research available on the informal sector in Pakistan. It is a useful attempt to capture internal differentiation within the informal sector which so far has mostly been studied as a homogeneous unit. Here it should be emphasised that the paper refers only to manufacturing activities in the informal sector and excludes the major bulk of informal sector activity in construction, transport, trade and services.

The authors subdivide manufacturing activity in the informal sector into two distinct groups on the basis of a set of criteria including employment size, level of capital investment, and contacts with the modern sector. The SS or self-sufficient segment of the informal economy is shown to comprise of traditional, family-based firms characterised by greater labour intensity and higher capital-output ratios as compared to the ML (mainly linked) sector which is more closely connected to the modern sector of the economy. The latter segment is shown to have higher average earnings and a greater proportion of non-family workers.

Unfortunately, the authors do not present the results of the survey on some other important features of the two sectors. Thus, very little is said about the differences in the two sectors with respect to technology used, the quality of products produced, and the rate of capital accumulation. Information provided in the survey on changes in the level of economic activity could also have been used to identify informal sector activities which have been expanding.

Moreover, some characteristics of the two sub-sectors mentioned by the authors, such as outward-backward linkages, inward-backward linkages, structural and conjectural instability of demand need further clarification. A more disaggregated analysis by activities could be used to illustrate these backward and forward linkages.

It would also have been useful to elaborate on the nature of the relationship between the ML units and the modern sector of the economy. Such linkages have been the source of considerable controversy in development literature where in a number of instances they have been shown to be exploitative and extremely unfavourable for the small firms. The system of subcontracting and outwork believed to have expanded significantly in recent years in Pakistan is seen as an important source of such contact between the two sectors. It would be interesting to know the extent of subcontracting work undertaken by firms in the sample.

The findings of the paper indicate marked differentials in earnings in the two sectors with the average wage in the SS sector being considerably below that in the ML sector. The earnings differential may partly be explained by a larger proportion of registered firms which are covered by government legislation in the ML group. Since the authors have not controlled for skill or educational levels the income difference may merely reflect a higher skill or educational content of the labour employed in ML uints. Hence, it is not clear whether lower wages reflect differences in the labour market processes or in the personal characteristics of the workers Further, earnings are only one aspect of employment another aspect of equal importance is job security. In this context the higher turnover of skilled and unskilled workers in the more modern sector needs to be explained.

Another distributional aspect of the informal sector which needs to be men tioned is the fact that it provides low-cost services and products which are directed mainly to the needs of low and middle-income groups.

In terms of the analytic usefulness of the classification the authors see the two sets of units as placed on different points on the continuum of productive activity whereby the SS units are in the process of transformation. However, it is not explained how these self-sufficient type of firms are supposed to transform into the more dynamic firms linked to the modern sector or the type of policy interventions required to bring about the transformation. From the policy point of view the division of the informal sector into these two distinct groups does not serve any useful function since instead of identifying informal business with greater growth potential or the right qualities for development, the authors conclude by recommending supportive policies across the board for both the SS and ML firms.

Shahnaz Kazi

Pakistan Institute of

Development Economics,

Islamabad 